\begin{tabular}{l|l|l} 
Jurnal Eksplorasi Akuntansi & Vol. 1, No 4, Seri A, November 2019, Hal 1617-1632
\end{tabular} \mid $\begin{aligned} & \text { ISSN : 2656-3649 (Online) } \\
& \text { http://jea.ppj.unp.ac.id/index.php/jea/issue/view/14 }\end{aligned}$

\title{
PENGARUH INDEPENDENCE COMMITMENT TERHADAP NIAT MELAKUKAN WHISTLEBLOWING DENGAN GROUP COHESION SEBAGAI VARIABEL MODERASI: SEBUAH STUDI EKSPERIMEN
}

\author{
Yulina Eka Safitri ${ }^{1}$, Sany Dwita ${ }^{2}$ \\ ${ }^{1}$ Alumni Jurusan Akuntansi Fakultas Ekonomi, Universitas Negeri Padang \\ ${ }^{2}$ Jurusan Akuntansi Fakultas Ekonomi, Universitas Negeri Padang \\ *Korespondensi: ekasafitriyulina@gmail.com
}

\begin{abstract}
This study aims to empirically examine the effect of independence commitment on the intention to do whistleblowing with group cohession as a moderating variable. This type of research is classified as quasi-experimental with $2 \times 2$ factorial experimental design. Data in this study were collected using a questionnaire on 80 accounting students of the Faculty of Economics, State University of Padang. Data analysis was performed using One way ANOVA and MRA. The results of this study conclude that independence commitment influences whistleblowing intentions, while group cohession does not moderate the relationship between independence commitment and whistleblowing. This is evidenced by the hypothesis test, where the H1 significance value is $0.001<0.005$ and the significance value at H2 is $0.184>0.005$.
\end{abstract}

Keywords: Independence Commitment; Group Cohession; Whistleblowing

How to cite (APA $6^{\text {th }}$ style)

Safitri, Y.A. \& Dwita, Sany. (2019). Pengaruh Independence Commitment terhadap Niat Melakukan Wistlebowing dengan Group Cohesion sebagai Variabel Moderasi. Jurnal Eksplorasi Akuntansi, 1(4), Seri A, 1617-1632.

\section{PENDAHULUAN}

Meningkatnya kejahatan kecurangan di berbagai belahan dunia telah mendorong berbagai negara dan asosiasi usaha untuk melakukan berbagai macam upaya pencegahan di sektor swasta maupun publik (KNKG, 2008). Salah satu upaya yang dapat dilakukan untuk mencegah kecurangan dan praktik ilegal adalah dengan melakukan whistleblowing. Menurut Near dan Micelli (1985), dalam Taylor dan Curtiz (2010), whistleblowing adalah pengungkapan oleh anggota organisasi atau karyawan atas suatu praktik-praktik ilegal, tidak bermoral, atau tanpa legitimasi di bawah kendali pimpinan kepada individu atau organisasi yang dapat menimbulkan efek tindakan perbaikan.

Whistleblowing bukanlah fenomena baru, namun sudah sejak lama terjadi di berbagai negara (Nurhidayat, 2017). Riset penelitian terdahulu sudah membuktikan pada kita bahwa penelitian tentang whistleblowing sudah banyak diteliti sebelumnya. Beberapa penelitian sebelumnya menyebutkan faktor pendorong individu melakukan whistleblowing diantaranya faktor organisasional, faktor individual, dan faktor demografi (Napitupulu dan Bernawati, 2016), tingkat keseriusan kecurangan (Bagustianto dan Nurkholis, 2014), komitmen profesional, 
pertimbangan etis (Joneta, 2016), intensitas moral (Zanaria, 2014), dimensi budaya (Finandari dan Wijayanto, 2016), mood (zhang, 2009).

Maraknya kecurangan yang terjadi membuat kepercayaan dari pemakai laporan keuangan menurun, sehingga tidak sedikit pula pihak pemangku kepentingan mempertanyakan komitmen independensi auditor (Trisnaningsih, 2007). Untuk menjaga kepercayaan pihak pemangku kepentingan auditor harus mempertahankan tingkat independensi yang tinggi (Arens, Elder, dan Beasley, 2012), artinya jika auditor tidak independen dalam mengumpulkan bukti audit dan mengevaluasi bahan bukti, kompetensi yang dimiliki seorang auditor tidak bernilai di mata pihak pemangku kepentingan. Selain itu, faktor penting yang dapat mempengaruhi auditor dalam mengungkapkan kecurangan adalah dengan memiliki sikap independensi (Biksa dan Wiratmaja, 2016).

Independensi adalah sikap yang tidak memihak dalam melaksanakan pengujian, evaluasi hasil pemeriksaan, dan penyusunan laporan keuangan (Arens, Elder, dan Beasley, 2012), ini artinya auditor berdiri sendiri dalam melaksanakan pekerjaanya untuk kepentingan umum bukan untuk kepentingan pihak tertentu. Auditor menganggap bahwa independensi merupakan kunci dari atribut profesi audit dan mempunyai keyakinan bahwa standar peraturan independensi auditor harus ketat mengikat dan menegakan domain akuntan publik, hal ini mengacu pada makna dari sikap independensi auditor (Gendron et al, 2006 dalam Alleyne et al, 2013). Jika seorang auditor memiliki komitmen dan dapat bersikap independen dalam melaksanakan audit tentu akan semakin mudah untuk melakukan whistleblowing apabila terdapat indikasi kecurangan, karena tingginya sikap independensi yang di pegang oleh auditor tersebut. Penelitian terdahulu memberi bukti pada kita bahwa independence commitment mempunyai pengaruh yang signifikan terhadap niat untuk melakukan whistleblowing (Alleyne et al, 2013; Gendron et al, 2006). Berbeda lagi dengan penelitian yang dilakukan oleh Alleyne et al (2019) yang menemukan tidak adanya pengaruh antara independence commitment dengan niat melakukan whistleblowing ketika dimoderasi oleh group cohesion.

Group cohesion menjelaskan bagaimana anggota kelompok saling berusaha untuk membentuk ikatan emosional, akrab, dan solid sehigga dapat mempertahankan anggota tetap berada dalam kelompok tersebut (Herlianto, 2013). Menurut Carron (1982), cohesion adalah kecenderungan anggota kelompok untuk membuat sebuah ikatan sosial yang mengakibatkan anggota kelompok saling bersatu untuk mencapai tujuan. Oleh karena itu di dalam sebuah kelompok yang kohesif anggota kelompok akan menunjukan perilaku yang lebih kooperatif dan lebih sensitif terhadap orang lain (Kidwell, Mossholder, dan Bennet, 1997 dalam Alleyne et al, 2019).

Pada tingkat individu, kelompok yang kohesif cenderung bertindak sebagai faktor pengendali yang mempengaruhi perilaku individu untuk untuk mematuhi norma dalam kelompok (Beal, Cohen, Burke, dan McLendon, 2003). Pernyataan tersebut didukung oleh penelitian yang dilakukan oleh Sanders (2004) dan Greenberger, Micelli, dan Cohen (1987), yang menyebutkan bahwa kohesi kelompok berhubungan positif dengan norma- norma dalam tim dan nilai- nilai sikap yang sesuai. Kohesi kelompok juga dapat mempengaruhi keputusan etis (Alleyne et al, 2019). Sebuah kelompok yang kohesif dapat menyebabkan anggota kelompok merasa perlu untuk mengambil tanggungjawab bersama untuk tindakan tidak etis atau etis kelompok (Allyne et al, 2019). Hal tersebut dapat disimpulkan bahwa seorang anggota dalam kelompok akan terlibat dalam perilaku tidak etis ketika tindakan terebut dapat merugikan kelompoknya. Sejalan dengan prosocial organizational theory (POB) juga menjelaskan seorang whistleblower adalah " 
prosocial behavior" yang tujuanya semata- mata untuk membantu pihak yang dirugikan dan untuk membuat sebuah organisasi lebih baik.

Penelitian yang dilakukan oleh Alleyne, Haniffa, dan Hudaib (2019), melakukan survey pada auditor yang ada di Barbados dalam penelitianya. Penelitian tersebut menguji pengaruh sikap terhadap perilaku, kontrol perilaku yang dirasakan, persetujuan moral, tanggungjawab personal, independence commitment, dan biaya pribadi pelaporan terhadap niat melakukan whistleblowing dengan group cohesion sebagai moderasi. Di dalam penelitian Alleyne et al (2019), masih terdapat hasil yang tidak sesuai dengan hipotesis yang di rencanakan yaitu independence commitment ditemukan hasil yang negatif dan tidak signifikan terhadap niat melakukan whistlebowing, namun hipotesis mendukung ketika dimoderasi oleh group cohesion. Hal ini memotivasi peneliti untuk mencoba menguji kembali penelitian yang dilakukan Alleyne et al (2019), namun dengan desain penelitian kuasi eksperimen yang akan disesuaikan dengan konteks di Indonesia.

Sanders (2004), juga menguji pengaruh group cohesion terhadap norma-norma dalam kelompok dan nilai-nilai tentang sikap perilaku. Penelitian dilakukan pada dua organisasi berbeda di Belanda. Hasil penelitian menunjukan bahwa group cohesion berhubungan positif dengan norma dalam kelompok dan nilai sikap pada salah satu organisasi, namun hasil berbeda pada organisasi lainya yang diteliti. Hasil penelitian Sanders (2004), sejalan dengan penelitian yang dilakukan oleh Herlianto (2013), yang meneliti pengaruh group cohesion terhadap dinamika kelompok, yang menyatakan bahwa terdapat pengaruh group cohesion terhadap dinamika kelompok.

\section{REVIEW LITERATUR DAN HIPOTESIS Whistleblowing}

Whistleblowing merupakan tindakan melaporkan suatu tindakan atau keputusan organisasi yang menyimpang dari peraturan dan undang-undang yang dilakukan oleh seseorang anggota organisasi itu kepada pihak lain seperti pemerintah, media masa, atau pihak-pihak yang berkaitan (Dozier, Brinker, Miceli, 1985). Pada dasarnya whistleblowing adalah salah satu cara yang efektif untuk mencegah dan mengurangi praktik yang bertentangan dengan etika maupun aturanaturan yang berlaku pada perusahaan yang kekuatan niat tergantung dari wistleblower sendiri (Napitulu dan Bernawati, 2016). Salah satu cara mengungkapkan kecurangan akuntansi sehingga dapat mengembalikan kepercayaan pemangku kepentingan adalah dengan melakukan whistleblowing (Zanaria, 2016). Di Indonesia untuk deteksi dini terkait pelanggaran yang terjadi di lingkungan Direktorat Jendral Pajak (DJP) sudah menerapkan whistleblowing system dengan harapan dapat mencegah dan mengurangi pelanggaran yang terjadi. Hal ini diharapkan mampu mendukung pencapaian sasaran penerimaan pajak yang optimal (Sulistyowati dan Pahlevi, 2018)

\section{Independence Commitment}

Independensi auditor secara tradisional telah dipahami sebagai masalah moral (Preston et al, 1995). Ini merupakan topik terkemuka dalam wacana etika kontemporer akuntansi, termasuk kode etik formal dan cerita yang sangat menarik untuk profesi akuntan (Everett et al, 2005). Di Amerika Serikat, menurut Securities and Exchange Commission (SEC) independensi auditor adalah sikap akuntan yang tidak memihak penghakiman pada semua isu-isu yang melibatkan akuntan.

Independensi merupakan sikap yang tidak memihak dalam melaksanakan pengujian, evaluasi hasil pemeriksaan, dan penyusunan laporan keuangan (Arens, Elder, dan Beasley, 
2012), ini artinya auditor berdiri sendiri dalam melaksanakan pekerjaanya untuk kepentingan umum bukan untuk kepentingan pihak tertentu. Dalam menentukan apakah seorang akuntan independen, komisi berhak memeriksa semua keadaan yang relevan, termasuk hubungan antara akuntan dan klien audit (Macey dan Sale, 2003 dalam Gendron et al, 2006).

\section{Group Cohession}

Menurut Carron (1982), cohesion adalah kecenderungan anggota kelompok untuk membuat sebuah ikatan sosial yang mengakibatkan anggota kelompok saling bersatu untuk mencapai tujuan. Oleh karena itu di dalam sebuah kelompok yang kohesif anggota kelompok akan menunjukan perilaku yang lebih kooperatif dan lebih sensitif terhadap orang lain (Kidwell, Mossholder, dan Bennet, 1997 dalam Alleyne et al, 2019). Anggota kelompok yang dengan kohesi tinggi cenderung kooperatif dan umumnya lebih mempertahankan integritas kelompoknya, sedangkan pada anggota kelompok dengan kohesi rendah lebih cenderung untuk bersikap independen dan kurang memperhatikan anggota kelompok yang lain (Herlianto, 2013).

\section{Theory of Planned Behavior (teori perilaku terencana)}

Theory of planned behavior (teori perilaku terencana) merupakan perluasan dari Theory of Reasoned Action (TRA) yang dikembangkan oleh Incek Ajsen dan Martin Fishbein (1980), dengan menambah persepsi kontrol perilaku (Zanaria, 2016). Teori perilaku terencana (TPB) beranggapan bahwa perilaku yang ditimbulkan individu yang tidak hanya di kontrol oleh individu itu sendiri (Krehastuti, 2014). Seseorang yang percaya bahwa dirinya tidak memiliki kesempatan untuk melaksanakan tingkah laku, lebih cenderung tidak memiliki intensi yang kuat untuk memunculkan tingkah laku tersebut, meskipun ia memiliki sikap terhadap tingkah laku yang positif dan yakin bahwa orang-orang yang disekitarnya mendukung (Cruz, 2015). TPB bertujuan untuk memperkirakan dampak dari niat seseorang untuk berperilaku, serta menjelaskan bagaimana perilaku nyata individu tersebut (Zanaria, 2016).

\section{Theory Prosocial organization behavior (POB)}

Selain Theory of Reasoned Action (TRA) yang dikembangkan oleh Incek Ajsen dan Martin Fishbein (1980), Procosial Organizational Behavior (POB) juga merupakan salah satu teori yang menjelaskan perilaku niat individu untuk melakukan whistleblowing dalam sebuah kelompok atau tim. Menurut Dozier dan Miceli (1985), perilaku prososial merupakan perilaku sosial positif yang bertujuan memberi manfaat kepada orang lain. Selain itu perilaku prososial juga memberikan keuntungan pada diri individu tersebut. Prosocial Organizational Behavior (POB) adalah perilaku yang ditimbulkan oleh anggota organisasi atau tim pada individu, kelompok, atau pada organisasi tersebut (Brief dan Motowidlo, 1986).

\section{Pengaruh Independence Commitment terhadap Whistleblowing}

Independence commitment mengacu pada sejauh mana akuntan individu menganggap bahwa independensi merupakan kunci dari atribut profesi, dan percaya bahwa peraturan harus ketat mengikat dan ditegakkan dalam lingkup akuntan publik (Gendron, Suddaby, Lam, 2006). Penelitian sebelumnya menunjukkan bahwa kunci dari audit terkait dengan independensi seorang auditor dan diketahui bahwa aspek regulasi sangat penting untuk mendapatkan kepercayaan pihak ketiga (Alleyne, Devonish, \& Alleyne, 2006). Hall, Smith, dan Langfield-Smith (2005), dalam Gendron et al (2006), mengatakan bahwa akuntan dengan independence commitment yang 
kuat untuk profesi mereka akan cenderung menjunjung tinggi kewajiban bermoral untuk terlibat dalam perilaku yang tidak etis dan menjadi whistleblower.

Independensi dalam laporan keuangan membuat auditor internal harus bebas dari niat untuk memodifikasi dampak dari fakta- fakta, dan bebas dari hambatan pihak yang ingin melakukan kecurangan dalam memberikan keputusan (Sawyer, 2006 dalam Windasari dan Juliarsa, 2016). Jika seorang auditor memiliki komitmen dan dapat bersikap independen dalam melaksanakan audit tentu akan semakin mudah untuk melakukan whistleblowing. Dari penjelasan diatas, peneliti berhipotesis:

H1: Independence commitment yang kuat lebih cenderung memiliki niat terhadap melakukan whistleblowing

\section{Group Cohession Memoderasi Hubungan Independence Commitment terhadap Niat Melakukan Whistleblowing}

Cohesion didefenisikan sebagai kecenderungan anggota kelompok untuk membuat ikatan sosial yang mengakibatkan anggota kelompok saling satu pikiran (Carron, Widmeyer,dan Brawley, 1985), dalam mencapai satu tujuan untuk kebutuhan anggota kelompok (Carron et al, 1985). Sebuah kelompok yang kohesif individu cenderung menjalankan suatu keputusan berdasarkan kesepakatan kelompok, dalam hal ini termasuk melakukan perilaku penyimpangan karna orientasi individu itu adalah untuk kesejahteraan kelompok (Hirschi dan Stark, 1968). Auditor yang merasakan dilema etis dan memiliki kohesi yang tinggi terhadap kelompok, akan lebih memilih untuk membuat kesepakatan terebih dahulu dengan kelompok mereka daripada mempertimbangkan keyakikan etis individu dan independensi dalam melaporkan kesalahan. Selain itu, auditor dengan kohesif kelompok yang tinggi cenderung menahan diri untuk tidak melakukan whistleblowing (Alleyne et al, 2019).

Singkatnya auditor dengan independence commitment yang kuat untuk profesi mereka akan cenderung menjunjung tinggi kewajiban bermoral untuk terlibat dalam perilaku yang tidak etis dan menjadi whistleblower, namun pada tingkat kelompok yang kohesif independence commitment cenderung melemah ketika group cohesion tinggi, karna orientasi individu tersebut tidak hanya pada profesi saja tetapi juga pada tujuan kelompok. Pada kelompok dengan kohesi rendah lebih independen dan kurang memperhatikan anggota lain (Herlianto, 2013). Dari penjelasan tersebut, peneliti berhipotesis:

H2: Kuatnya independence commitment terhadap niat melakukan whistleblowing akan melemah ketika dimoderasi oleh group cohesion

\section{METODE PENELITIAN}

\section{Desain penelitian}

Penelitian ini menggunakan desain kuasi eksperimen dengan pendekatan kuantitatif. Penelitian eksperimen merupakan penelitian yang sistematis, logis, dan teliti dalam mengontrol kondisi dan digunakan untuk melihat sejauh mana pengaruh variabel bebas mempengaruhi variabel terikat (Riyanto, 1996; Saputra, 2018). Menurut Arikunto (2006), pendekatan kuantitatif merupakan metode penelitian yang berdasarkan pada filsafat positivisme, yang digunakan untuk meneliti populasi atau sampel, analisis datanya bersifat kuantitatif/statistik dengan maksud untuk menguji hipotesis yang telah dibuat, sedangkan data kuantitatif merupakan data berbentuk angka, atau data yang diangkakan, sehingga dalam penelitian kuantitatif dituntut menggunakan angka, mulai dari pengumpulan data, penafsiran terhadap data, serta penampilan dari hasilnya. 
Desain kuasi eksperimen digunakan untuk mendapatkan kelompok kontrol yang digunakan penelitian. Desain kuasi eksperimen digunakan dalam penelitian ini dengan mencobakan perlakuan pada dua independence commitment (kuat dan lemah) dan dengan desain 2 X 2 faktorial. Variabel bebas dalam penelitian ini independence commitment, variabel moderasi group cohession. Berikut desain faktorial.

Tabel 1.

Desain faktorial 2X2

\begin{tabular}{|c|c|c|c|}
\hline & & Group c & \\
\hline & & Kuat & Lemah \\
\hline Independence & Kuat & WSB 1 & WSB 2 \\
\hline commitment & Lemah & WSB 3 & WSB 4 \\
\hline
\end{tabular}

Keterangan:

WSB 1 : Niat melakukan whistleblowing pada group cohession kuat dengan indepenence commitment kuat.

WSB 2 : Niat melakukan whistleblowing pada group cohession lemah dengan independence commitment kuat.

WSB 3: Niat melakukan whistleblowing pada group cohession kuat dengan independence commitment lemah

WSB 4: Niat melakukan whistleblowing pada group cohession lemah dengan independence commitment lemah.

\section{Jenis dan sumber data}

Dalam penelitian ini menggunakan data kuantitatif, sehingga data yang diperoleh dari laporan responden secara individu yang berupa sikap, opini, pengalaman responden melalui kuisioner yang peneliti bagikan. Sumber data yang digunakan dalam penelitian ini adalah data primer. Data primer merupakan data yang diperoleh dari sumber pertama seperti perorangan atau individu. Sumber data dalam penelitian ini adalah mahasiswa akuntansi yang terdaftar tahun 2016 Fakultas Ekonomi Universitas Negeri Padang.

\section{Teknik Pengumpulan data}

Teknik pengumpulan data merupakan langkah yang dilakukan peneliti untuk mendapatkan data. Teknik pengumpulan data dalam penelitian ini dilakukan dengan menyebarkan kuesioner secara langsung pada mahasiswa. Kuesioner dibagikan disesuaikan dengan jadwal mata kuliah responden. Tujuanya adalah agar tercapainya tingkat pengembalian kuesioner secara keseluruhan oleh partisipan. Pembagian kuesioner dilakukan didalam kelas dengan memanfaatkan waktu luang setelah jam kuliah partisipan. Dalam pengisian kuesioner akan langsung diawasi dan dipandu oleh peneliti dalam pengisiannya agar tidak terjadi kesalahan dalam pengisian.

\section{Instrumen Penelitian}

Instrumen dalam penelitian ini diadopsi dari penelitian Alleyne et al (2019), yang dikembangkan dari kuesioner Bahasa Inggris asli dengan menggunakan teknik penerjemahan kembali. Dua individu yang berbeda dengan penguasaan Bahasa Inggris dan Bahasa Indonesia yang baik terlibat dalam menerjemahkan kembali kuosioner ini. Metode ini sangat umum digunakan oleh penelitian terdahulu. Tujuan dari penggunaan metode ini adalah untuk memastikan konsistensi 
makna antara kuesioner asli dengan yang diterjemahkan (Dwita, Helmy, dan Chreisviyanny, 2018).

Instrumen penelitian ini terdiri dari 2 bentuk, yaitu lampiran A dan Lampiran B. Pada tiap awal masing-masing lampiran, peneliti menyediakan penjelasan mengenai maksud dan tujuan penelitian ini. Setelah itu partisipan diminta untuk mengisi identitas. Peneliti juga menambahkan pada masing-masing lampiran mengenai devenisi dari variabel whistleblowing, independence commitment dan group cohesion untuk pengetahuan umum bagi responden. Dalam eksperimen ini, partisipan diminta untuk berperan sebagai orang ketiga tunggal dari sebuah kasus. Partisipan diminta untuk merasakan, mengamati, dan mempelajari informasi tentang keputusan Andi selaku manajer audit terhadap tawaran dari klien audit untuk menjadi pengawas keuangan perusahaan. Dalam skenario penelitian ini seorang senior audit (partisipan) ditugaskan untuk bekerja pada perikatan audit dengan perusahaan klien, diketahui bahwa manajer audit (Andi) ditawari posisi pengawas keuangan oleh perusahaan yang sedang di audit. Namun, Andi menerima tawaran itu (untuk independence commitment lemah) pada lampiran 1, dan menolak tawaran itu (untuk independence commitment kuat) pada lampiran 2, sementara dia masih melanjutkan tanggungjawab sebagai manajer audit. partisipan diminta untuk berasumsi bahwa Andi adalah manajer dari tim audit partisipan saat ini.

Selain penyajian skenario dalam kuesioner juga disajikan pernyataan terkait sikap dan niat terhadap whistleblowing, independence commitment, dan group cohesion yang diukur dengan skala likert point 1-7, dengan keterangan untuk variabel sikap dan niat terhadap whistleblowing point 1 menyatakan "tidak sangat benar" dan point 7 menyatakan "sangat benar", variabel independence commitment point 1 menyatakan "sangat tidak setuju" dan point 7 "sangat setuju dan variabel moderasi yaitu group cohesion point 1 menyatakan "tidak sama sekali" dan point 7 menyatakan "sangat banyak".

\section{Uji Coba Instrumen}

Uji coba instrumen (pilot test) sebelum kuesioner dibagikan pada responden penelitian, diuji terlebih dahulu untuk mengevaluasi apakah pernyataan relevan dan mudah dimengerti atau tidak oleh responden dengan menghitung validitas dan reliabilitas kuesioner uji coba. Uji coba instrumen ini diberikan pada 20 mahasiswa akuntansi di Universitas Negeri Padang di dalam populasi penelitian namun tidak termasuk responden penelitian.

\section{Uji Validitas}

Uji validitas digunakan untuk mengukur sah atau valid tidaknya suatu kuesioner. Suatu kuesioner dinyatakan valid jika pertanyaan pada kuesioner mampu untuk mengungkapkan sesuatu yang diukur oleh kuesioner tersebut (Ghozali, 2013). Dalam penelitian ini, pengukuran validitas akan diukur menggunakan bantuan program SPSS Windows Release 21.0 dengan metode correlation pearson. Jika hasil skor butir pernyataan dalam instrumen berkorelasi positif dengan total skor konstruk sehingga instrumen dapat dikatakan valid atau hasilnya menjunjukkan sig. 2 tailed < signifikansi $(0,05)$ maka dinyatakan valid.

\section{Uji Reliabilitas}

Reliabilitas merupakan alat untuk mengukur suatu kuesioner yaindikator dari variabel atau konstruk. Suatu kuesioner dikatakan reliabel atau handal jika jawaban seseorang terhadap pernyataan adalah konsisten atau stabil dari waktu ke waktu (Ghozali, 2013:47). Pengukuran reliabilitas dalam penelitian ini menggunakan metode One Shot atau pengukuran sekali saja 
yaitu, pengukurannya hanya sekali saja dan kemudian hasilnya dibandingkan dengan pertanyaan lain atau mengukur korelasi antar jawaban pertanyaan. SPSS Windows Release 21.0 memberikan fasilitas untuk mengukur reliabilitas dengan uji statistik Cronbach Alpha $(\alpha)$. Suatu kontruk atau variabel dikatakan reliabel jika memberikan nilai Cronbach Alpha > 0,70 (Ghozali, 2013:48).

\section{Prosedur Penelitian}

Untuk mengetahui kecenderungan perilaku manajer bawah dalam melakukan senjangan anggaran, penelitian eksperimen ini dibagi menjadi 3 tahapan, antara lain:

1. Membagi angket dan kuesioner penelitian kepad4 partisipan. Peneliti masuk ke dalam kelas partisipan lalu membagikan angket treatment, kuesioner.

2. Pengarahan serta penjelasan mengenai tugas dan peran peneliti memberikan penjelasan mengenai penelitian yang akan dilakukan serta pengarahan mengenai tata cara pengisian angket serta kuesioner agar partisipan mendapatkan pemahaman mengenai apa yang harus dilakukan selama eksperimen. Peneliti juga memberikan penjelasan mengenai tugas dan peran peneliti selama eksperimen.

3. Pengisian data identitas rersponden berisi tentang pertanyaan umum terkait data diri responden.

4. Treatment pada masing-masing kelompok perlakuan Setelah menyelesaikan tugas kasus berdasarkan soal kasus yang didapatkan. Kemudian partisipan diminta untuk membaca kasus secara seksama untuk masing-masing kelompok perlakuan kode etik. Dan selanjutnya responden diminta untuk menjawab pernyataan yang terkait dengan niat berperilaku, independence commitment, whistleblowing dan skala keinginan sosial.

\section{Defenisi Operasional Variabel dan Pengukuranya Variable dependen (Y)}

Dalam penelitian ini yang menjadi variabel dependen adalah whistleblowing. Whistleblowing adalah pengungkapan kecurangan yang melawan hukum, perbuatan tidak etis/tidak bermoral atau perbuatan yang dapat merugikan organisasi maupun pemangku kepentingan, yang dilakukan oleh karyawan atau pimpinan organisasi kepada pimpinan organisasi atau lembaga lain yang dapat mengambil tindakan atas pelanggaran, biasanya dilakukan secara rahasia (confidential).Variabel ini diukur dengan menggunakan skala likert untuk menentukan sikap dan niat terhadap whistleblowing yang terdapat pada masing-masing lampiran setelah skenario dengan menetapkan point dalam skala likert 1-7 ( $1=$ sangat tidak benar, 7 = sangat benar $)$.

\section{Variabel Independen (X1)}

Dalam penelitian ini yang menjadi variabel independen adalah independence commitment. Independence commitment adalah komitmen seorang auditro untuk bersikap tidak memihak dalam melaksanakan pengujian, evaluasi hasil pemeriksaan, dan penyusunan laporan keuangan, ini artinya auditor berdiri sendiri dalam melaksanakan pekerjaanya untuk kepentingan umum bukan untuk kepentingan pihak tertentu. Independence commitment diukur menggunakan skala likert atas pertanyaan yang terkait dengan skenario pada masing-masing lampiran, dengan menggunakan skala likert 1-7 ( $1=$ benar-benar tidak setuju, 7 = sangat setuju $)$.

\section{Variabel Moderating}

Dalam penelitian ini yang menjadi variabel moderasi adalah group cohession. Group cohession adalah kecenderungan anggota pada sebuah kelompok untuk membuat sebuah ikatan sosial yang 
menimbulkan rasa untuk saling bersatu dalam mencapai tujuan kelompok. Group cohession diukur menggunakan skala likert atas pertanyaan yang terkait dengan skenario pada masingmasing lampiran, dengan menggunakan skala likert 1-7 (1= tidak sama sekali, $7=$ sangat banyak).

\section{Teknik analisis data \\ Uji Asumsi Klasik}

a. Uji Normalitas

Uji normalitas dilakukan untuk melihat apakah dalam variabel bebas dan terikat memiliki data yang terdistribusi secara normal atau tidak. Untuk hasil model terbaik adalah jika memiliki distribusi data yang normal atau mendekati normal.

\section{b. Uji Homogenitas}

Uji homogenitas digunakan untuk mengetahui sama atau tidaknya varian dari beberapa sampel. Uji ini biasanya dilakukan sebagai syarat dalam analisis ANOVA. Jika nilai siginifikansi < 0,05 maka dikatakan bahwa varian dari dua kelompok lebih populasi data tidak sama. Begitu sebaliknya jika nilai signifikansi > 0,05 maka dikatakan bahwa dua kelompok lebih populasi data sama/ homogen.

\section{Uji Hipotesis}

Pengujian hipotesis pertama dan kedua dalam penelitian ini menggunakan alat uji:

a. Analysis of Variance (ANOVA).

ANOVA adalah prosedur pengolahan data yang dilakukan untuk menguji perbedaan nilai rata-rata beberapa grup (lebih dari dua). Dalam penelitian ini ANOVA digunakan untuk membandingkan kecenderungan individu untuk melakukan whistleblowing apabila berada dalam kondisi independence commitment yang berbeda, yang mana dmanipulasikan menjadi independence commitment kuat dan lemah.

\section{b. Analisis Moderated Regression Analysis (MRA)}

Analisis Moderated Regression Analysis (MRA) atau uji interaksi merupakan aplikasi khusus regresi linear berganda dimana dalam persamaan regresinya mengandung unsur interaksi (perkalian dua atau lebih variabel independen). Seperti diketahui bahwa analisis regresi digunakan untuk mengetahui pengaruh antara variabel bebas (Independence) terhadap variabel terikat (dependen). Kali ini analisis regresi dilakukan dengan menambah satu variabel lagi yaitu variabel moderator atau mederating. Pada dasarnya variabel moderasi adalah variabel independence yang dapat memperkuat atau memperlemah hubungan diantara variabel independen terhadap variabel dependen.

\section{HASIL PENELITIAN DAN PEMBAHASAN Gambaran Umum Objek Penelitian}

Partisipan dalam penelitian ini adalah mahasiswa Akuntansi Fakultas Ekonomi UNP tahun masuk 2016 yang telah mengambil mata kuliah etika bisnis, akuntansi manajemen dan auditing. Partisipan diasumsikan mampu memahami dan dapat menempatkan diri mereka sebagai anggota dalam sebuah tim audit pada KAP ketika dihadapkan pada sebuah kasus pelanggaran di lingkungan kerjanya.

Sebelum peneliti melakukan olah data atas hasil dari penyebaran kuesioner, peneliti terlebih dahulu melakukan pemeriksaan terhadap kelengkapan pengisian data demografi. 
Berdasarkan kriteria kuesioner yang bisa diolah yang ditetapkan sebelumnya, maka dapat dikumpulkan sebanyak 80 kuesioner yang dapat diolah dan sebanyak 11 kuesioner yang tidak bisa diolah karena partisipan mungkin kurang memahami dan kurang memperhatikan intruksi yag diberikan. Sehingga dapat disimpulkan bahwa angka response rate yang diperoleh dalam penelitan ini adalah sebesar $87,91 \%$.

\section{Analisis Deskriptif}

\section{Analisis Deskriptif Variabel Whistleblowing (Y)}

Pendeskripsian pada kasus penelitian dilakukan sebelum melaksanakan pengujian data statistik lebih lanjut agar dapat memberikan gambaran mengenai kasus yang akan diteliti. Dari hasil analisis deskriptif variabel whistleblowing diketahui bahwa jumlah responden dalam penelitian ini adalah 80 responden $(\mathrm{N})$, dari 80 responden ini nilai terendah (Minimum) dan Tertinggi (maksimum) yaitu sebesar 14 dan 70 . Rata-rata nilai nilai dari 80 responden atau mean sebesar 52,3 dengan standar deviasi sebesar 16,237 dan varian 26,531. Berikut hasil analisis deskriptif.

Tabel 2

Analisis Deskriptif Variabel Whistleblowing

\begin{tabular}{|l|l|l|l|l|l|l|}
\hline & N & Min & Max & Mean & $\begin{array}{l}\text { Std. } \\
\text { Deviation }\end{array}$ & Variance \\
\hline WB1 & 80 & 1 & 7 & 5,09 & 1,780 & 3,169 \\
\hline WB2 & 80 & 2 & 7 & 5,20 & 1,657 & 2,744 \\
\hline WB3 & 80 & 1 & 7 & 5,45 & 1,558 & 2,428 \\
\hline WB4 & 80 & 1 & 7 & 4,84 & 1,579 & 2,492 \\
\hline WB5 & 80 & 1 & 7 & 5,54 & 1,706 & 2,910 \\
\hline WB6 & 80 & 2 & 7 & 5,24 & 1,486 & 2,209 \\
\hline WB7 & 80 & 2 & 7 & 5,51 & 1,484 & 2,202 \\
\hline WB8 & 80 & 2 & 7 & 5,65 & 1,552 & 2,408 \\
\hline WB9 & 80 & 1 & 7 & 5,09 & 1,528 & 2,334 \\
\hline WB10 & 80 & 1 & 7 & 4,69 & 1,907 & 3,635 \\
\hline $\begin{array}{l}\text { Total } \\
\text { skor }\end{array}$ & 80 & 14 & 70 & 52,3 & 16,237 & 26,531 \\
\hline
\end{tabular}

Sumber: data primer yang diolah, 2019

\section{Analisis Deskriptif Variabel Independence Commitment (X1) dan Group cohesion}

Independence commitment diukur berdasarkan tingkat kuat dan lemah yang terkandung dalam masing-masing item skenario kasus tentang independensi auditor, untuk independence commitement kuat (menolak) diberi kode 1, sedangkan untuk independence lemah (menerima) diberi kode 2. Group cohesion diukur berdasarkan tingkat kuat dan lemah yang terkandung dalam masing-masing item skenario kasus tentang independensi auditor, untuk group cohesion kuat diberi kode 1, sedangkan untuk group cohesion lemah diberi kode 2.

Dari hasil analisis deskriptif variabel independence commitment diketahui bahwa jumlah responden dalam penelitian ini adalah 80 responden $(\mathrm{N})$, dari 80 responden ini nilai terendah (Minimum) dan Tertinggi (maksimum) yaitu sebesar 1 dan 2. Rata-rata nilai nilai dari 80 responden atau mean sebesar 1,54 dengan standar deviasi sebesar 0,502 dan varian 0,252. Berdasarkan hasil deskriptif variabel group cohesion diketahui bahwa jumlah responden dalam penelitian ini adalah 80 responden $(\mathrm{N})$, dari 80 responden ini nilai terendah (Minimum) dan Tertinggi (maksimum) yaitu sebesar 1 dan 2 . Rata-rata nilai nilai dari 80 responden atau mean sebesar 1,54 dengan standar deviasi sebesar 0,502 dan varian 0,252. Berikut hasil analisis deskriptif. 
Tabel 3

Analisis Deskriptif Variabel independence commitment dan group cohesion

\begin{tabular}{|c|c|c|c|c|c|c|}
\hline & $\mathrm{N}$ & Min & Max & Mean & Std. Deviation & Variance \\
\hline $\begin{array}{l}\text { Independence } \\
\text { commitment } \\
\text { Valid } \\
\text { (listwise) }\end{array}$ & $\begin{array}{l}80 \\
80\end{array}$ & 1 & 2 & 1,54 &, 502 &, 252 \\
\hline Group cohesion & 80 & 1 & 2 & 1,54 & ,502 & 252 \\
\hline $\begin{array}{ll}\text { Valid } & \mathrm{N} \\
\text { (Listwise) } & \end{array}$ & 80 & & & & & \\
\hline
\end{tabular}

Sumber: data primer diolah, 2019

\section{Hasil Uji Asumsi Klasik}

\section{Uji Asumsi Klasik Normalitas}

Uji normalitas bertujuan untuk mengetahui apakah data whistleblowing (Y), independence commitment (X) dan group cohesion (Moderasi) berdistribusi normal atau tidak. Dasar pengambilan keputusan data dalam penelitian ini menggunakan kolmogorof smirnov, yaitu nilai signifikansi >0,05, maka dapat disimpulkan bahwa data tersebut berdistribusi normal. Begitu juga sebaliknya jika signifikansi $<0.05$ maka data tersebut tidak normal. Berdasarkan hasil olah data dapat diketahui bahwa nilai signifikansi (sig) one sample kolmogorov smirnov test adalah sebesar 0, 062, berdasarkan dasar pengambilan keputusan dalam uji normalitas, yaitu >0,05, sehingga dapat disimpulkan bahwa data diatas berdistribusi normal karena 0,062>0,05. Berikut hasil uji asumsi klasik normalitas.

Tabel 4

Uji Normalitas One-Sample Kolmogorof-Smirnov Test

\begin{tabular}{|l|l|l|}
\hline \multicolumn{2}{|l|}{} & Unstadardized Residual \\
\hline $\mathrm{N}$ & Mean & 80 \\
\hline \multirow{2}{*}{ Normal Parameters ${ }^{a, b}$} & Std. Deviation & $0 \mathrm{E}-7$ \\
\hline \multirow{2}{*}{$\begin{array}{l}\text { Most Extreme } \\
\text { Differences }\end{array}$} & Absolute & 10,43327477 \\
\cline { 2 - 3 } & Positive &, 147 \\
\cline { 2 - 3 } & Negative & -094 \\
\hline Kolmogorov-Smirnov Z &,- 147 \\
\hline Asymp. Sig. (2-tailed) & 1,317 \\
\hline
\end{tabular}

Sumber: data primer diolah, 2019

\section{Uji Asumsi Klasik Homogenitas}

Uji homogenitas bertujuan untuk mengetahui apakah varian dari beberapa populasi data sama atau tidak. Pengujian homogenitas dilakukan dengan cara uji Levene's Test. Dasar pengambilan keputusan pengujian homogenitas yaitu jika nilai signifikansi >0,05 maka dikatakan bahwa varian data adalah homogen. Hasil uji homogenitas dapat dilihat bahwa nilai signifikansi independence commitment adalah sebesar 0,031 yang berarti $<0,05$. Hal tersebut dapat disimpulkan bahwa data penelitian ini memiliki varian yang tidak sama atau tidak homogen, sehingga syarat asumsi tidak terpenuhi. Berdasarkan hasil olah data diketahui bahwa nilai signifikansi group cohesion sebesar 0,671 yang berarti > 0,05. Hal tersebut dapat disimpulkan bahwa data penelitian ini memiliki varian yang sama atau homogen, sehingga syarat asumsi terpenuhi. Berikut hasil uji homogenitas. 
Tabel 5

Uji Homogenitas independence commitment dan group cohesion

\begin{tabular}{|l|l|l|l|l|}
\hline & $\begin{array}{l}\text { Levene } \\
\text { statistic }\end{array}$ & $d f 1$ & Df2 & Sig. \\
\hline $\begin{array}{l}\text { Independence } \\
\text { commitment }\end{array}$ & 4,802 & 1 & 78 &, 031 \\
\hline Group cohesion &, 182 & 1 & 78 &, 671 \\
\hline
\end{tabular}

Sumber: data primer diolah, 2019

\section{Hasil Uji Hipotesis \\ Hipotesis pertama}

Teknik analisis data yang digunakan untuk menguji kebenaran hipotesis yang diajukan adalah dengan menggunakan analisis uji ANOVA (Analysis Of Variance). ANOVA merupakan salah satu uji komparatif yang digunakan untuk menguji perbedaan mean (rata-rata) data lebih dari dua kelompok. Hipotesis pertama dalam penelitian ini melakukan pengujian dengan uji analisis varians one way ANOVA. ANOVA satu arah menguji secara satu-persatu dari masing-masing variabel $\mathrm{X}_{1}$ terhadap $\mathrm{Y}$.

Variabel pertama yang diuji dalam penelitian ini melakukan pengujian dengan uji analisis varians one way ANOVA. Hipotesis pertama $\left(\mathrm{H}_{1}\right)$ yang dirumuskan dalam penelitian ini adalah independence commitment yang kuat cenderung melakukan niat whistleblowing. Hasil uji parametrik dan non-parametrik, pada uji parametrik menunjukkan mean senilai 2080,280 yang diperkuat dengan signifikansi analisis one way ANOVA yaitu sebesar 0,000 kurang dari 0,005. Hal ini membuktikan independence commitment yang kuat memiliki pengaruh terhadap niat melakukan whistleblowing adalah terdukung.

Hipotesis pertama dianalisis dengan menambahkan uji tambahan yaitu uji nonparametrik. Pengujian non-parametrik digunakan bertujuan untuk menambah kelengkapan hasil penelitian karena adanya ketidaklengkapan item khusus yang tidak terdistribusi secara normal atau tidak homogen. Uji non-parametrik yang digunakan adalah uji kruskall wallis yang bertujuan untuk uji dua kelompok atau lebih berbeda dengan skala ordinal atau nominal.

Hasil olah data menunjukkan mean rank atas independence commitment kuat dan independence commitment lemah yang berbeda yaitu mean rank independence commitment lemah lebih rendah dari pada mean rank independence commitment kuat sebesar 30,81 dan 48,84 serta diperkuat dengan nilai $p$ value yang ditunjukkan oleh nilai asymp.Sig yang dihasilkan adalah 0,001. Dalam hal ini nilai $p$ value sebesar 0,001 dimana kurang dari batas kritis 0,05 yang berarti menerima $\mathrm{H}_{1}$ atau independence commitment memberikan pengaruh terhadap niat melakukan whistleblowing. Dengan demikian dari hasil analisis tersebut dapat ditarik kesimpulan bahwa hipotesis pertama diterima. Berikut hasil uji parametrik dan non parametrik.

Tabel 6

Ringkasan Hasil Uji Parametrik dan Non Parametrik

\begin{tabular}{|l|l|l|l|l|l|l|}
\hline \multicolumn{2}{|l|}{ Uji Parametrik } & \multicolumn{4}{l|}{ Uji Non-Parametrik } \\
\hline \multicolumn{2}{|l|}{ Uji One Way ANOVA } & \multicolumn{2}{l|}{ Uji Kruskall Wallis } \\
\hline & Mean & $\mathrm{F}$ & Sig & & Mean Rank & Sig \\
\hline $\begin{array}{l}\text { Independence } \\
\text { commitment }\end{array}$ & 2080,280 & 15,960 & 0,000 & Independence commitment kuat & 30,81 & \multirow{2}{*}{0,001} \\
\cline { 4 - 7 } & & & Independence commitment lemah & 48,84 & \\
\hline
\end{tabular}

Sumber: data primer diolah, 2019 


\section{Hipotesis Kedua}

Teknik analisis data yang digunakan untuk menguji kebenaran hipotesis yang diaajukan adalah dengan menggunakan analisis uji interaksi atau MRA (Moderate Regression Analysis). MRA atau uji interaksi merupakan aplikasi khusus regresi linear berganda dimana dalam persamaan regresinya mengandung unsur interaksi (perkalian dua atau lebih variabel independen). Seperti diketahui bahwa analisis regresi digunakan untuk mengetahui pengaruh antara variabel bebas (Independence) terhadap variabel terikat (dependen). Kali ini analisis regresi dilakukan dengan menambah satu variabel lagi yaitu variabel moderator. Pada dasarnya variabel moderasi adalah variabel independen yang dapat memperkuat atau memperlemah hubungan diantara variabel independen terhadap variabel dependen.

Hipotesis kedua yang diuji dalam penelitian ini melakukan pengujian dengan uji interaksi atau MRA. Hipotesis kedua yang dirumuskan dalam penelitian ini adalah kuatnya independence commitment terhadap niat melakukan whistleblowing akan melemah ketika dimoderasi oleh group cohesion. Berdasarkan hasil output model summary koefesien determinasi besarnya adjusted R Square adalah 0,314, hal ini berarti 31,4\% Variasi whistleblowing yang dapat dijelaskan oleh variabel independence commitment, group cohesion dan Moderate. Sedangkan sisanya $(100 \%-31,4 \%=68,6 \%)$ dijelaskan oleh variabel lain diluar model. Pada hasil output coefficient, menunjukan bahwa nilai sig pada moderate yaitu sebesar $0,184>0,05$. Dengan begitu dapat disimpulkan bahwa kuatnya independence commitment terhadap niat melakukan whistleblowing akan melemah ketika dimoderasi oleh group cohesion yang berarti hipotesis kedua ditolak. Berikut hasil uji MRA.

Tabel 7

Ringkasan Hasil Uji MRA

\begin{tabular}{|c|c|c|c|c|c|c|}
\hline \multicolumn{7}{|c|}{ Model Summary } \\
\hline \multirow{2}{*}{\multicolumn{2}{|c|}{$\begin{array}{l}\text { Model } \\
1\end{array}$}} & \multicolumn{2}{|l|}{$R$} & $R$ square & $\begin{array}{l}\text { Adjusted } R \\
\text { Square }\end{array}$ & $\begin{array}{l}\text { Std. Error of } \\
\text { the Estimate }\end{array}$ \\
\hline & & \multicolumn{2}{|l|}{, $560^{\mathrm{a}}$} & ,314 & ,287 & 10,514 \\
\hline \multicolumn{7}{|c|}{ Coefficients $^{a}$} \\
\hline \multirow{2}{*}{\multicolumn{2}{|c|}{ Model }} & \multicolumn{2}{|c|}{$\begin{array}{l}\text { Unstandardized } \\
\text { Coefficients }\end{array}$} & $\begin{array}{l}\text { Standardized } \\
\text { Coefficients }\end{array}$ & $\mathrm{T}$ & Sig. \\
\hline & & $B$ & Std. Error & Beta & & \\
\hline \multirow{4}{*}{1} & (Constant) & 83,578 & 60,366 & & 1,385 &, 170 \\
\hline & $\mathrm{X}$ & $-1,471$ & 2,372 &,- 461 &,- 620 & ,537 \\
\hline & $\mathrm{M}$ & $-3,265$ & 2,637 &,- 907 & $-1,238$ & 220 \\
\hline & MODERATE & ,138 &, 103 & 1,555 & 1,340 & 184 \\
\hline
\end{tabular}

Sumber: data primer diolah, 2019

\section{Pembahasan}

Perbedaan Pengaruh Independence Commitment terhadap Niat Melakukan Whistleblowing Hasil pengujian hipotesis menunjukkan perbedaan pengaruh independence commitment kuat dan lemah terhadap niat melakukan whistleblowing. Hal ini dapat dilihat dari hasil pengolahan data menggunakan uji one way ANOVA. Hasil tabel menunjukkan F hitung sebesar 15,960 dan diperkuat dengan nilai signifikansi yang diperoleh sebesar $0,000<0,05$.

Independence commitment mempengaruhi whistleblowing karena muncul sebagai kewajiban bermoral untuk terlibat dalam perilaku yang tidak etis dan menjadi whistleblower akibat melakukan whistleblowing (Gendron et al, 2006). Independence commitment kuat cenderung akan membuat individu atau partisipan dalam penelitian ini untuk melakukan 
tindakan whistleblowing, sedangkan pada independence commitment lemah cenderung untuk tidak melakukan whistleblowing.

Independence commitment kuat memiliki cenderung melakukan niat whistleblowing, ini artinya adalah semakin tinggi independence commitment maka akan semakin tinggi pula niat melakukan whistleblowing, begitu juga sebaliknya. Penelitian terdahulu memberi bukti pada kita bahwa independence commitment mempunyai pengaruh yang signifikan terhadap niat untuk melakukan whistleblowing (Alleyne et al, 2013., Gendron et al, 2006). Hasil ini konsisten dengan hasil penelitian peneliti. Berbeda lagi dengan penelitian yang dilakukan oleh Alleyne et al (2019), yang menemukan tidak adanya pengaruh antara independence commitment dengan niat melakukan whistleblowing ketika dimoderasi oleh group cohesion.

\section{Perbedaan Pengaruh Group Cohession terhadap Niat Melakukan Whistleblowing}

Hasil pengujian hipotesis menunjukkan perbedaan pengaruh group cohesion kuat dan lemah terhadap niat melakukan whistleblowing. Hal ini dapat dilihat dari hasil pengolahan data menggunakan uji MRA. Hasil output coefficient menunjukkan nilai sig pada moderate yaitu sebesar 0,184>0,05, sedangkan hasil output model summary koefesien determinasi besarnya adjusted R Square adalah 0,314, hal ini berarti 31,4\% Variasi whistleblowing yang dapat dijelaskan oleh variabel independence commitment, group cohesion dan Moderate. Sedangkan sisanya $(100 \%-31,4 \%=68,6 \%)$ dijelaskan oleh variabel lain diluar model.

Group cohession tidak memoderasi hubungan antara independence commitment terhadap whistleblowing karena ketika independence commitment kuat cenderung menjunjung tinggi kewajiban bermoral untuk terlibat dalam perilaku yang tidak etis dan menjadi whistleblower akibat melakukan whistleblowing, meskipun ketika group cohesion tinggi. Penelitian terdahulu memberi bukti pada kita bahwa group cohession tidak memoderasi hubungan antara independence commitment terhadap niat untuk melakukan whistleblowing (Alleyne et al, 2019). Hasil ini konsisten dengan hasil penelitian yang dilakukan oleh peneliti, dimana peneliti juga menemukan tidak adanya pengaruh antara independence commitment dengan niat melakukan whistleblowing ketika dimoderasi oleh group cohesion.

\section{KESIMPULAN DAN SARAN \\ Kesimpulan}

Berdasarkan hasil temuan penelitian dan pengujian hipotesis yang telah dilakukan dapat disimpulkan sebagai berikut (1) Individu yang memiliki independence commitment kuat akan lebih cenderung menunjukkan niat melakukan whistleblowing dibandingkan individu yang memiliki independence commitment yang lemah, (2) Individu yang memiliki indepndence commitment kuat terhadap niat melakukan whistleblowing tidak dimoderasi oleh group cohesion.

\section{Keterbatasan}

Penelitian ini memiliki keterbatasan antara lain sebagai berikut (1) responden dalam penelitian ini sebagian kecil kurang memahami petunjuk pengisian instrumen penelitian sehingga sebagian kecil data tidak layak diolah atau tidak dapat dipakai, (2) populasi dalam penelitian ini juga masih sebatas mahasiswa akuntansi S1 Fakultas Ekonomi UNP tahun masuk 2016

\section{Saran}

Berdasarkan penelitian ini maka bisa diajukan beberapa saran yang dihasilkan dari penelitian ini (1) peneliti selanjutnya dapat menambah populasi penelitian agar hasilnya lebih generalisasi, (2) 
peneliti selanjutnya agar dapat menggunakan variabel independen lain yang mungkin memiliki pengaruh terhadap niat melakukan whistleblowing seperti religiusitas dan power distance

\section{DAFTAR PUSTAKA}

Ajzen, I. (1988). Attitudes, personality, and behavior. Milton Keynes: Open University Press.

Alleyne, P., Devonish, D. and Alleyne, P.G. (2006). Perceptions of auditor independence in Barbados. Managerial Auditing Journal, 21(6), 621-635.

Alleyne, P., Haniffa, R., \& Hudaib, M. (2019). Does group cohesion moderate auditors' whistleblowing intentions?. Journal of International Accounting, Auditing and Taxation, 34, 69- 90.

Alleyne, P., Hudaib, M., \& Pike, R. (2013). Towards a conceptual model of whistle-blowing intentions among external auditors. The British Accounting Riview.

Arens, A. A., Elder, R. J., \& Beasley, M. S. (2012). Auditing \& jasa assurance: Pendekatan terintegrasi. (Edisi Kelimabelas). Jakarta. Erlangga.

Bagustianto, R., Nurkholis, (2014). Faktor-faktor yang mempengaruhi minat. pegawai negeri sipil (PNS) untuk melakukan tindakan whistle-blowing. Jurnal Ilmiah Mahasiswa FEB, $3(1)$.

Beal, D., Cohen, R., Burke, M., \& McLendon, C. (2003). Cohesion and performance in groups: A metaanalytic clarification of construct relations. Journal of Applied Psychology, 88(6). 989-1004.

Biksa, I. A. I., Wiratmaja, I. D. N. (2016). Pengaruh pengalaman, independensi, skeptisisme profesional auditor pada pendeteksian kecurangan. E- Jurnal Akuntansi Universitas Udayana, 17(3), 2384-2415.

Brief, A. P., Motowidlo, S. J. (1986). Prosocial organizational behaviors. The Academy of management review, 11(4), 710-725.

Carron, A.V., Widmeyer, W.N., \& Brawley, L.R. (1985). The development of an instrument to assess cohesion in sport teams: The group environment questionnaire. Journal of Sport Psychology, 7(3), 244-266.

Cruz, L. (2015). Aplikasi theory of planned behavior dakam membangkitkan niat berwirausaha bagi mahasiswa fakultas ekonomi UNPAZ, DILI Timor Leste. Jurnal Ekonomi dan Bisnis. Universitas Udayana.

Dozier, J. B., Miceli, M P. (1985). Potential predictors of whistleBlowing: A prosocial behavior perspective. The Academy of Management Review, 10(4), 823-836.

Dwita, S., Helmy, H., Chreisviyanny, C. (2018). The Influence of Gender and Personality on 'Holier-Than-Thou' Perception Bias among Minangkabau Accountants, Journal of Economics and Management, 12 (1), 1-15.

Finandari, D., Wijayanto, T. (2016). Analisis pengaruh dimensi budaya terhadap niat melakukan whistleblowing perbandingan antara mahasiswa dan Engineer. Jurnal Teknosains, 6,(1), 44-52.

Gendron, Y., Suddaby, R., \& Lam, H. (2006). An examination of the ethical commitment of professional accountants to auditor independence. Journal of Business Ethics, 64, 169193.

Ghozali, I. (2013). Aplikasi Analisis Multivariate dengan Program IBM SPSS 21. Semarang: Badan Penerbit Universitas Diponegoro. 
Herlianto, P. 2013. Hubungan antara kohesivitas kelompok denngan dinamika kelompok dalam proses bimbingan kelompok pada siswa SMP negeri 13 semarang. Skripsi. Fakultas Ilmu Pendidikan. Universitas Negeri Semarang. Semarang.

Hirschi, T., Stark, R. (1969). Hellfire and delinquency. Social Problems, 17(2), 202-213.

http://www.ecgi.org/codes/documents/indonesia "Komite Nasional Kebijakan Governance (KNKG)". Diakses tanggal 22 Agustus 2019.

Joneta, C. (2016). Pengaruh komitmen profesional dan pertimbangan etis tterhadap intensi melakukan whistleblowing: Locus of control sebagai variabel moderasi. Jurnal Manajemen Operasional, 13(1).

Krehastuti, D. K. (2014). Analisis faktor-faktor yang mempengaruhi intensi auditor untuk melakukan whistleblowing (Studi Empiris Pada KAP Di Semarang). Jurnal Universitas Diponegoro

Napitupulu, B., Bernawati, Y. (2016). Pengaruh faktor organisasional, faktor individual, dan faktor demografi terhadap intensi whistleblowing. E-Journal Universitas Airlangga.

Sanders, K. (2004). Playing truant within organizations: Informal relationships, work ethics and absenteeism. Journal of Managerial Psychology, 19(2), 136-155.

Sulistyowati, S. L. \& Pahlevi, R. W. (2018). Pengaruh good governace dan whistleblowing system terhadap kepatuhan wajib pajak dengan risiko sanksi pajak sebagai moderasi (Studi Empiris Pada Wajib Pajak Di Kabupaten Sleman). Jurnal Bisnis Teori Dan Implementasi, 9(1).

Taylor, E. Z., Curtis, M. B. (2010). An examination of the layers workplace influence in ethical judgement: Whistleblowing likelihood and perseverance in public accounting. Journal of Business Ethics, 93, 21-37.

Widasari, M. Y., Juliarsa, G. (2016). Pengaruh independensi, dan profesionalisme auditor internal dalam mencegah kecurangan pada BPR di Kabupaten Bandung. E- Jurnal Akuntansi Universitas Udayana, 17(3), 1924- 1952.

Zanaria, Y. (2016). Pengaruh profesionalisme audit, intensitas moral untuk melakukan tindakan whistleblowing (Studi pada di Indonesia). Jurnal Akuntansi, 12(1).

Zhang, J., Chiu, R., Wei. L. ( 2009). On whistleblowing judgement an intention. Journal of Managerial Psychology, 24(7), 627-649. 